\title{
Value Added Decomposition of Chinese Provincial Exports and Its Assessment of True Comparative Advantage: A Case Study of Manufacturing in Jiangsu Province
}

\author{
Hui Chen, Jian Xu \\ School of Business, Nanjing Normal University, Nanjing, China \\ Email: chenhui0707@163.com
}

How to cite this paper: Chen, $\mathrm{H}$. and $\mathrm{Xu}$, J. (2019) Value Added Decomposition of Chinese Provincial Exports and Its Assessment of True Comparative Advantage: A Case Study of Manufacturing in Jiangsu Province. Open Journal of Social Sciences, 7, 380-399.

https://doi.org/10.4236/jss.2019.73032

Received: February 22, 2019

Accepted: March 22, 2019

Published: March 25, 2019

Copyright $\odot 2019$ by author(s) and Scientific Research Publishing Inc. This work is licensed under the Creative Commons Attribution International License (CC BY 4.0).

http://creativecommons.org/licenses/by/4.0/

(c) $\underset{\mathrm{EY}}{\mathrm{C}}$ Open Access

\begin{abstract}
The Sino-US trade conflict, the collapse of economic globalization and the reconstruction of global value chains have enhanced the necessity and urgency of building an open and connected, self-controllable, domestic value chain. Jiangsu is a major province and a large open province. The goal, path and measures for Jiangsu to build an independent and controllable advanced manufacturing system will have typical reference value. Based on the KWW trade value added decomposition framework, the World Input-Output Table (WIOT) and the inter-regional input-output tables of 30 provinces in China, Jiangsu's return domestic value added, foreign value added, province value added and other provinces' value added in Jiangsu's manufacturing exports are estimated. Meanwhile, the regional linkages and changes of Jiangsu's manufacturing exports with the rest of the provinces are also analyzed. The results show that the value added of imports from Jiangsu exports is higher than that of other provinces, which indicates that the "foreign circulation" of Jiangsu's economy is stronger than "domestic circulation" though the situation is always changing in recent years. The Yangtze River Delta region is the core space for Jiangsu to build manufacturing industry chain. The Yangtze River Economic Belt and the Huaihai Economic Zone, which is the part of new Silk Road, are two important extended spaces for Jiangsu to build up NVC. Finally, On the basis of the decomposition of export value added, the industries with real comparative advantages in 16 major manufacturing industries in Jiangsu Province are evaluated. Both the advantages and disadvantages of Jiangsu's value chain upgrading at the industrial level are unveiled.
\end{abstract}




\section{Keywords}

Value Added Decomposition, Comparative Advantage of Value Added, Jiangsu Manufacturing, Regional Association, Value Chain

\section{Introduction}

Since the mid-to-late 1980s, due to the difference in the cost of labor or other factors, the degree of improved divisibility of the production process owning to technological advancement, and the rapid decline in trade costs and the division of the global value chain gradually occupy a dominant position in the world market and become the main carrier and manifestation of this round of economic globalization. Just as the economic globalization appeared in history which helps to bring growth and prosperity to major countries, they also inevitably cause imbalances in interests and structural distortions between country and country. Besides, they also may trigger a series of economic turmoil such as the financial crisis and the European debt crisis. What's more, they may cause anti-globalization trends such as isolationism, protectionism and populism at the same time. China's original global value chain, which is dominated by multinational corporations in developed countries, faces enormous obstacles and uncertainties in the process of industrial from embedding, extending to upgrading. The necessity and urgency of enhancing the control of key technologies and the integration of industrial chains and building, integrating, and enhancing the controllable domestic value chain have been strengthened. As a major manufacturing province and a large open province, Jiangsu's objectives, paths and measures for building an independent, controllable and advanced manufacturing system may have typical reference value. This is also the background for this paper.

Since the reform and opening up, the coastal provinces and cities represented by Jiangsu and Guangdong have gradually embarked on a development path from the township industry. That is, a development path of "market-for-technology" manufacturing expansion and upgrading can be realized by the "three to one supplement" processing trade and the large-scale introduction of foreign investment. A large number of empirical studies (Luolin Wang et al., 2000; Xiaojuan Jiang, 2002; Erzhen Zhang, 2005) [1] [2] [3] show that the foreign capital investment spillover effect is achieved by embedding the global value chain (GVC). In particular, after new century, Jiangsu focuses on the selective investment of the world's top 500 companies, which played a significant role in promoting product upgrades, technology upgrades, and structural upgrades in Jiangsu's manufacturing industry. Coupled with Jiangsu's good manufacturing base, excellent industrial supporting capacity and advanced infrastructure, the scale and competitiveness of Jiangsu's manufacturing industry, as well as the export scale of mechanical and electrical products and high-tech products have 
been in the forefront of the country since 2004. Jiangsu is a major manufacturing province and open economy province. However, some small East Asian economies that have good relations with the United States and do not constitute an overall economic competition for the United States have realized the upgrading of processes and products and mastered the core processes or technologies of some components through long-term efforts after embedding GVC. They are still subordinate to the control and governance of the entire value chain. Some foreign scholars have earlier doubted the effectiveness of a large economy like China climbing along the "smile curve" (Gereffi, 1999) [4]. Domestic scholars (Xiaohua Li, 2004; Jian Xu, 2005; Xinqiao Ping, 2007) [5] [6] [7] studied the effects of FDI's growth and development, whether the market can change to technology, and how to switch to technology. Zhibiao Liu et al. (2007) [8] firstly proposed the necessity of cracking the low-end capture of global value chain by constructing national value chain (NVC). Besides, the mechanism and path of NVC construction were systematically studied by Li Genqiang Li, Wenqing Pan (2016) [9] and Feng Li (2017) [10]. At the practical and policy level, with the volatility of the global economy and the formation of the new normal of China's economy, Jiangsu's manufacturing industry lacks key technologies, and thus the problem of "big but not strong" is increasingly apparent. Industrial clusters, value chain integration, and industry standards are constrained by multinational corporations. Emerging industries such as new energy, new materials and artificial intelligence are once again eager to deal with assembly, rushing, and overcapacity. In 2016, Jiangsu issued the "Made in China 2025 Jiangsu Action Plan" and proposed the goal of "building an advanced manufacturing base". In 2018, Jiangsu clearly stated that it should focus on "building an independent and controllable advanced manufacturing system" to improve key technology control, industrial cluster driving, industrial chain integration, information technology leading the manufacturing industry and international industry standards setting. In fact, the system emphasizes the systematic of chaining into chains, and the key link of the value chain is often the high value added link. The status and trends of this system can be assessed by value added decomposition. Therefore, the essence of this system should be built based on the position and existing comparative advantages of different industries in Jiangsu in the global division of labor system and the NVC that is open to GVC.

There are some studies on the theory and method of trade value added decomposition. The "statistical fantasy" where the current trade interest and trade balance are extremely mismatched under the global value chain division system has gradually exposed the shortcomings of traditional statistical methods based on gross value trade. In March 2012, the WTO and OECD officially confirmed the concept of "Trade in Value Added". This research on statistical methods has become one of the hotspots of GVC research. Hummels, Ishii, and Yi (2001, HIY hereinafter) [11] firstly studied this problem. They defined vertical specialization as VS, using a single-country input-output table to calculate and analyze the 
value source of a country's exports. Koopman et al. (2012) [12] distinguished between processing trade and non-processing trade exports, and analyzed the source of China's value added exports through China's non-competitive input-output table. Johnson and Noguera (2012) [13] used GTAP data to define and measure the value added export (VAX) and value added exports ratio (VAXR), which is the value added export/gross value export. Wang, Wei, and Zhu (2013) [14] constructed a set of gross trade decomposition frameworks from bilateral countries and industries. Koopman, Wang and Wei (2014, KWW hereinafter) [15] firstly constructed the decomposition framework of a country's exports at the national level. The gross value of a country's exports can be decomposed into three parts, i.e., domestic value added (DVA), foreign value added (FVS), and return domestic value added (RDV). Subsequent research on the method of decomposing value added exports is basically based on the refinement and expansion of this framework. The domestic academic community's attention and research on the value chain trade statistics method is basically synchronized with the international, and more emphasis on practical application and its policy implications. Zunyi Liu et al. (2007) [16] first added processing trade to the non-competitive input-output model to measure China's trade surplus with the United States. It is pointed out that China's trade surplus with the United States has not brought greater contributions to China's trade benefits. Jun Deng (2013) [17] reassessed the actual export competitiveness of China's manufacturing industry based on the World Input-Output Database. In his study, value added trade rather than traditional gross value trade is targeted. Kun Wang and Han Liao (2016) [18] also decomposed the vertical spillover of FDI based on the non-competitive input-output table. It is believed that China should pay attention to improving the local procurement rate of foreign-funded enterprises. Besides, China should also give full play to the backward linkage effect of foreign enterprises through the purchase of domestic intermediate products or services provided by upstream industries. Lan Wang (2018) [19] constructed a bilateral trade benefit accounting framework that integrated value added trade and ownership trade. Meanwhile, the true trade interests of China's exports to the United States were also excluded the contribution of foreign companies.

To clarify the correlation between industry, technology, and input-output in various provinces and regions in China is a fundamental issue in building and integrating NVC. Before the value chain research and value added decomposition methods are mature and widely used, domestic scholars have made useful explorations on how to construct NVC. Shaojun Zhang et al. (2010) [20] believed that regional integration can be used to extend the part of GVC in the country to build our own value chain. Qiang Wu, Zhibiao Liu, etc. (2011) [21] believed that building NVC is the driving force for regional economic integration in China's Yangtze River Delta region. Huge domestic market can cultivate NVC. This is undoubtedly an important study of macroeconomic and distribution system issues. These studies have a wide range of perspectives, but do not 
solve the basic problems of building NVC. The KWW value added decomposition method is a trade value decomposition accounting system. Its' more important value is to analyze the composition and mechanism of the value chain. It can be applied between countries and international regions, and it can also be applied in domestic provinces and regions. This application is more valuable for a large economy like China with many regions, large regional endowment and regional development gap. Qingyi Su (2016) [22] draw on the value added decomposition method of Wang, Wei and Zhu (2013) and made a pioneering study in this area. The World Input-Output Table and the China's interregional non-competitive input-output table were used to carry out the Chinese province. The value added comparative advantage of four representative industries in each province was also measured. His research is based on China's Input-Output Table in 2007, which is far away. The study only gives the gross data of foreign provinces value added from the province's value added exports. There is no decomposition in the regional association, and the comparative advantage of the four representative industries is territorial value added comparative advantage. The role of foreign capitals are not considered. Fangyi Li (2016) [23] based on China's Interregional Non-competitive Input-Output Table in 2010. The value added exports was calculated and its impact on the industrial structure from national and regional scales was analyzed. The research by Genqiang $\mathrm{Li}$ and Wenqing Pan (2016) [24] reveals the differences in GVC and NVC between China's coastal areas and inland areas. The research on the dynamic perspective of Hongfu Ni and Jiechang Xia (2016) [25] further confirmed the conclusions of Li and Pan (2016). Wenqing Pan and Genqiang Li (2018) [26] combined China's seven major regions and five Asia-Pacific economies. The interface between NVC and GVC is the key point. The spatial correlation between the 12 research subjects was comprehensively analyzed. The conclusions of directionality and polarity are important evidences for the expected conclusions of this paper.

In summary, this paper has the basis of theoretical support and method improvement. The innovation value and marginal contribution of this paper are mainly reflected in the following three aspects:

First, the application of value added decomposition and input-output technology directly to Jiangsu "building an independent and controllable manufacturing system" is a new perspective of national value chain research, and also a problem-oriented and application-oriented research. Whether it is a global value chain or a national value chain, external view is a grand narrative, but it must be implemented in specific countries, regions and especially enterprise entities. By value added decomposition and specific industry analysis, leading companies and local governments in relevant industries can clearly see their true competitiveness.

Second, regional association research is a refined research on spatial direction hints. Based on the gross data and large-area data of Qingyi Su, Wenqing Pan and Genqiang $\mathrm{Li}$, the input-output relationships and dynamics between Jiangsu and other provinces and regions provide a reference of the spatial layout for the 
NVC system coordinated with other regions in China.

Third, the real value added comparative advantage research is an extended study of "finding the family". Compared with the research on the territorial added value comparative advantage of Qingyi Su (2016), the paper considers the proportion of foreign capitals in the manufacturing industry and evaluates Jiangsu's truly competitive industry that is ownership comparative advantage industry. And the input-output tables in 2007, 2010 and 2012 are used to assess the true value added comparative advantage of 16 industries.

\section{Value Added Decomposition Framework, Value Added Comparative Advantage (RCA) and Data Source}

\subsection{Value Added Exports Decomposition Framework}

In the case of processing trade and value chain division of trade, intermediate inputs need to distinguish between intermediate inputs from the country (the province) and foreign (external provinces), and non-competitive input-output tables must be used. Based on the conditional assumptions of KWW (2014) and WWZ (2013), and the provincial-level value-added decomposition framework established by Qingyi Su (2016), the value-added exports decomposition formula of a country is derived shown in Table 1.

Table 1 is a general table of input-output tables.

In this non-competitive input-output table with $\mathrm{G}$ regions (30 in this paper) and $\mathrm{N}$ industries (16 in this paper), $X_{i j}$ is a matrix of $N * N$ indicating that the output of each industry in the region $i$ is used as the amount of intermediate inputs by the relevant industries in the region $j . E_{i}, X_{i}$ and $Y_{i j}$ respectively represent the region's export vector, gross output vector and the region in which each industry is used as the final demand. $V_{j}, M_{j}$ and $R_{j}$ are matrixs of $1 * N$. They respectively represent the local value added, import value added and return value added in the production process of regional $j . A_{i j} \mathrm{j}$ represents the input-output coefficient matrix corresponding to $X_{i j} . \tilde{V}_{j}, \tilde{M}_{j}$ and $\tilde{R}_{j}$ represent local value added coefficient matrix, import value added coefficient matrix and return value added coefficient matrix. $B$ represents the Leonid's inverse matrix. $E$ represents the exit matrix. Then the local value added matrix $\tilde{V}_{j} B E$, the import value added matrix $\tilde{M}_{j} B E$ and the return value added matrix $\tilde{R}_{j} B E$ can be expressed as:

$$
\begin{aligned}
\tilde{V}_{j} B E & =\left(\begin{array}{cccc}
\tilde{V}_{1} B_{11} E_{1} & \tilde{V}_{1} B_{12} E_{2} & \cdots & \tilde{V}_{1} B_{1 G} E_{G} \\
\tilde{V}_{2} B_{21} E_{1} & \tilde{V}_{2} B_{22} E_{2} & \cdots & \tilde{V}_{2} B_{2 G} E_{G} \\
\vdots & \vdots & \ddots & \vdots \\
\tilde{V}_{G} B_{G 1} E_{1} & \tilde{V}_{G} B_{G 2} E_{2} & \cdots & \tilde{V}_{G} B_{G G} E_{G}
\end{array}\right) \\
\tilde{M}_{j} B E & =\left(\begin{array}{cccc}
\tilde{M}_{1} B_{11} E_{1} & \tilde{M}_{1} B_{12} E_{2} & \cdots & \tilde{M}_{1} B_{1 G} E_{G} \\
\tilde{M}_{2} B_{21} E_{1} & \tilde{M}_{2} B_{22} E_{2} & \cdots & \tilde{M}_{2} B_{2 G} E_{G} \\
\vdots & \vdots & \ddots & \vdots \\
\tilde{M}_{G} B_{G 1} E_{1} & \tilde{M}_{G} B_{G 2} E_{2} & \cdots & \tilde{M}_{G} B_{G G} E_{G}
\end{array}\right)
\end{aligned}
$$


Table 1. General expressions of non-competitive input-output tables.

\begin{tabular}{|c|c|c|c|c|c|c|c|c|c|c|c|}
\hline \multirow{2}{*}{\multicolumn{2}{|c|}{$\begin{array}{l}\text { Output } \\
\text { Input }\end{array}$}} & \multicolumn{4}{|c|}{ Intermediate use } & \multicolumn{5}{|c|}{ Final use } & \multirow{2}{*}{$\begin{array}{l}\text { Total } \\
\text { output }\end{array}$} \\
\hline & & Area 1 & Area 2 & $\ldots$ & Area G & Area 1 & Area 2 & $\ldots$ & Area G & Export & \\
\hline \multirow{6}{*}{$\begin{array}{l}\text { Intermediate } \\
\text { investment }\end{array}$} & Area 1 & $\mathrm{X}_{11}$ & $\mathrm{X}_{12}$ & $\cdots$ & $\mathrm{X}_{1 \mathrm{G}}$ & $\mathrm{Y}_{11}$ & $\mathrm{Y}_{12}$ & $\cdots$ & $Y_{1 G}$ & $\mathrm{E}_{1}$ & $\mathrm{X}_{1}$ \\
\hline & Area 2 & $\mathrm{X}_{21}$ & $\mathrm{X}_{22}$ & $\cdots$ & $\mathrm{X}_{2 \mathrm{G}}$ & $Y_{21}$ & $\mathrm{Y}_{22}$ & $\ldots$ & $\mathrm{Y}_{2 \mathrm{G}}$ & $\mathrm{E}_{2}$ & $\mathrm{X}_{2}$ \\
\hline & $\cdots$ & $\cdots$ & $\cdots$ & $\cdots$ & $\cdots$ & $\cdots$ & $\cdots$ & $\cdots$ & $\cdots$ & $\cdots$ & $\cdots$ \\
\hline & Area G & $\mathrm{X}_{\mathrm{G} 1}$ & $\mathrm{X}_{\mathrm{G} 2}$ & $\ldots$ & $\mathrm{X}_{\mathrm{GG}}$ & $\mathrm{Y}_{\mathrm{G} 1}$ & $\mathrm{Y}_{\mathrm{G} 2}$ & $\cdots$ & $\mathrm{Y}_{\mathrm{GG}}$ & $\mathrm{E}_{\mathrm{G}}$ & $\mathrm{X}_{\mathrm{G}}$ \\
\hline & Foreign & $\mathrm{M}_{1}$ & $\mathrm{M}_{1}$ & $\ldots$ & $\mathrm{M}_{\mathrm{G}}$ & & & & & & \\
\hline & Return & $\mathrm{R}_{1}$ & $\mathrm{R}_{2}$ & $\cdots$ & $\mathrm{R}_{\mathrm{G}}$ & & & & & & \\
\hline \multicolumn{2}{|c|}{ Value Added } & $\mathrm{V}_{1}$ & $\mathrm{~V}_{2}$ & $\cdots$ & $\mathrm{V}_{\mathrm{G}}$ & & & & & & \\
\hline \multicolumn{2}{|c|}{ Total investment } & $X_{1}^{\prime}$ & $X_{2}^{\prime}$ & $\ldots$ & $X_{G}^{\prime}$ & & & & & & \\
\hline
\end{tabular}

$$
\tilde{R}_{j} B E=\left(\begin{array}{cccc}
\tilde{R}_{1} B_{11} E_{1} & \tilde{R}_{1} B_{12} E_{2} & \cdots & \tilde{R}_{1} B_{1 G} E_{G} \\
\tilde{R}_{2} B_{21} E_{1} & \tilde{R}_{2} B_{21} E_{2} & \cdots & \tilde{R}_{2} B_{2 G} E_{G} \\
\vdots & \vdots & \ddots & \vdots \\
\tilde{R}_{G} B_{G 1} E_{1} & \tilde{R}_{G} B_{G 2} E_{2} & \cdots & \tilde{R}_{G} B_{G G} E_{G}
\end{array}\right)
$$

According to the above matrix, the province's value added $D V A_{i}$, the external provinces' value added $D V S_{i}$ (domestic vertical specialization), the import value added $F V S_{i}$ (foreign vertical specialization) and the return value added $R D V_{i}$ of province is value added exports. The formula is:

$$
\begin{gathered}
D V A_{i}=\tilde{V}_{i} B_{i i} E_{i} \\
D V S_{i}=\sum_{j \neq i}^{G} \tilde{V}_{j} B_{j i} E_{i} \\
F V S_{i}=\sum_{j=1}^{G} \tilde{M}_{j} B_{j i} E_{i} \cdots \\
R D V_{i}=\sum_{j=1}^{G} \tilde{R}_{j} B_{j i} E_{i} \cdots
\end{gathered}
$$

\subsection{Value Added Comparative Advantage (RCA)}

The Revealed Comparative Advantage Index is a tool commonly used in international trade to measure whether a product or industry in a country (region) has comparative advantage, the size of comparative advantage and its dynamic changes. The calculation method for this index is:

A product's export value in one country (region) accounts for the proportion of this country's (regional) gross export value, divided by this product's export value in the world market accounts for the world market's gross export value. According to the comparative advantage theoretical model, if RCA $>1$, it means that the product or industry has comparative advantage, and the larger the value, the stronger the comparative advantage. Traditional and classic studies generally use the gross value of trade to measure the revealed comparative advantage. Under GVC conditions, a country's exports contain different degrees of foreign import value, and the comparative advantage in terms of gross trade value may 
be distorted. Under the value-added decomposition framework, the national (local) value added exports can be used to calculate the RCA, making the comparison of the comparative advantage closer to the real situation. According to the basic principles of comparative advantage theory, products or industries that can continue to export stably are usually products or industries with comparative advantages. The revealed comparative advantage of industry $n$ of province $i$ can be calculated by formula (5), where $\mathrm{G}$ is the number of provinces (autonomous regions, municipalities) and $\mathrm{N}$ is the number of industries.

$$
R C A_{i n}=\frac{E_{i n} / \sum_{n=1}^{N} E_{i n}}{\sum_{i=1}^{G} E_{i n} / \sum_{i=1}^{G} \sum_{n=1}^{N} E_{i n}}
$$

Equation (5) can be used to calculate the gross value comparative advantage and can also be used to calculate the value added comparative advantage. Regardless of the comparative advantage, it is territorial value added comparative advantage, that is, the comparative advantage of the industries located within the geographical scope of the province, including both local and foreign components. Building self-controllable manufacturing system must consider the realities of the local ownership industries' position and comparative advantage in the global value chain system. To this end, we have attempted to establish and calculate the index of the proportion of foreign investment in the 16 manufacturing sub-sectors in Jiangsu to the gross fixed asset investment of the industry, that is, in combination with the value added RCA, to assess the true comparative advantages of various industries.

\subsection{Data Sources and Processing Methods}

First, the decomposition of Jiangsu's value added exports, using data from 56 industries in 44 countries in the World Input-Output Table (WIOT) latest released by World Input-Output Database (WIOD) in 2016, combined with the input and output series data of 30 departments of the inter-regional non-competitive input-output tables $(2007,2010,2012$, Weidong Liu, etc.) of 30 provinces, autonomous regions and municipalities in China compiled by the Key Laboratory of Regional Sustainable Development Analysis and Simulation of Chinese Academy of Sciences. This table divides all industries in China into 6 departments and 30 departments. The reason why this paper chooses to use 30 tables to decompose the added-value is that the results are more detailed and accurate. Although Qingyi Su (2016) estimates that the return value added is not high, considering that Jiangsu is a foreign-invested province, and some pillar industries in Jiangsu such as IT are high-value chain division industries, the return value added is measured.

The calculation of the value added comparative advantage is calculated after the data of local value added of Jiangsu's export, combined with the gross export value data and the sub-industry data of the relevant years of China Customs Database and Jiangsu Statistical Yearbook. According to the data of "Foreign Direct 
Investment by Industry" and "Fixed Assets Investment by Industry" published in Jiangsu Statistical Yearbook, the proportion of foreign investment in 16 manufacturing sub-sectors in Jiangsu is calculated. Jiangsu introduced foreign capital earlier, and the large-scale introduction of foreign capital began in 2002 after China joined the WTO. Since the Jiangsu Statistical Yearbook began to have investment data by industry in 2003, the gross data of 2002 according to the industry data of 2003 were processed. The data $F D I_{n} / T F I_{n}$ of the three periods 2002-2007, 2002-2010 and 2002-2012 were calculated to correspond to the data of the three years 2007, 2010 and 2012. This data processing method is not reasonable, but it is basically consistent with the actual situation in Jiangsu.

The relevant data sources and processing methods need to explain that the four databases (tables) used in this paper do not have the same industry classification. Therefore, the industry classification of the inter-regional input-output table of the Chinese Academy of Sciences is the standard. The other three series of data are sorted.

\section{Decomposition, Calculation Results and Analysis}

\subsection{The "Outer Circulation" of Jiangsu Manufacturing Industry Is Stronger Than "Internal Circulation"}

Table 2 shows the decomposition results of Jiangsu's manufacturing value added exports. Table 3 shows the value added from the province's and other provinces (autonomous regions, municipalities) of the 16 major manufacturing exports. The results of the calculation are consistent with or basically consistent with the results of the same year data of Qingyi Su and Wenqing Pan.

As can be seen from the data in Table 2, Jiangsu is a province with a relatively high degree of embedded in the global value chain. In the three years of 2007, 2010 and 2012, the import value added of manufacturing exports in two years reached above $30 \%$. As can be seen from the data in Table 3, the top five sub-sectors of Jiangsu's manufacturing exports are: communications equipment, computers and other electronic equipment manufacturing, textile clothing, footwear and hat manufacturing, chemical industry, metallurgy and metal products industry, general and special equipment manufacturing. Among them, computer communication equipment and parts manufacturing is a typical global value chain industry. Jiangsu's export industry structure is same with Guangdong in the same period and similar to Shanghai, so it is comparable. In these three years, the local value-added rate of Jiangsu's manufacturing exports remains between $53.21 \%$ and $56.32 \%$, higher than that of Guangdong, which is also an open economy province, and Shanghai, which is in the Yangtze River Delta region. The corresponding data for Guangdong in 2007 is $40.68 \%$ and Shanghai is $42.76 \%$. It shows that the position of Jiangsu manufacturing industry in the global value chain may be relatively higher, the value chain in the province is longer, and there may be relatively stronger technical control and value chain integration. In these three years, Jiangsu's province's value-added rate continues 
Table 2. Sources of Jiangsu's manufacturing value added exports and its share of gross value of exports.

\begin{tabular}{ccccccccc}
\hline \multirow{2}{*}{ Years } & \multicolumn{3}{c}{$\begin{array}{c}\text { Source of Value Added } \\
\text { Exports (100 million) }\end{array}$} & \multicolumn{4}{c}{$\begin{array}{c}\text { The Proportion of Each Added Value } \\
\text { to the Gross Value of Exports (\%) }\end{array}$} \\
\cline { 2 - 9 } & DVA & DVS & FVS & RDV & DVAS & DVSS & FVSS & RDVS \\
\hline 2007 & 7877 & 2213 & 4686 & 28 & 53.21 & 14.95 & 31.65 & 0.19 \\
2010 & 10012 & 2897 & 5573 & 54 & 54.02 & 15.63 & 30.06 & 0.29 \\
2012 & 12081 & 4565 & 4740 & 64 & 56.32 & 21.28 & 22.10 & 0.30 \\
\hline
\end{tabular}

Note: Calculated according to formula (1), (2), (3), (4) by Matlab.

Table 3. Value added of the province and other provinces in the value added of Jiangsu manufacturing segment industry exports.

\begin{tabular}{|c|c|c|c|c|c|c|}
\hline \multirow{2}{*}{ Manufacturing Industry } & \multicolumn{2}{|c|}{2007} & \multicolumn{2}{|c|}{2010} & \multicolumn{2}{|c|}{2012} \\
\hline & Jiangsu & Others & Jiangsu & Others & Jiangsu & Others \\
\hline Food and tobacco processing industry & 88 & 55 & 183 & 86 & 175 & 296 \\
\hline Textile industry & 773 & 115 & 728 & 92 & 646 & 119 \\
\hline $\begin{array}{l}\text { Clothing, shoes, hats, leather and } \\
\text { other products industry }\end{array}$ & 305 & 13 & 313 & 16 & 535 & 25 \\
\hline $\begin{array}{l}\text { Wood processing and furniture } \\
\text { manufacturing }\end{array}$ & 98 & 39 & 127 & 32 & 149 & 35 \\
\hline $\begin{array}{l}\text { Paper printing, cultural and } \\
\text { educational sporting goods } \\
\text { manufacturing }\end{array}$ & 133 & 29 & 174 & 37 & 210 & 75 \\
\hline $\begin{array}{l}\text { Petroleum processing, coking and } \\
\text { nuclear fuel processing industry }\end{array}$ & 45 & 69 & 109 & 103 & 79 & 107 \\
\hline chemical industry & 714 & 172 & 901 & 184 & 1639 & 452 \\
\hline $\begin{array}{l}\text { Non-metallic mineral } \\
\text { products industry }\end{array}$ & 74 & 51 & 133 & 89 & 172 & 151 \\
\hline $\begin{array}{l}\text { Metal smelting and rolling processing } \\
\text { industry }\end{array}$ & 441 & 202 & 484 & 320 & 738 & 501 \\
\hline Metal products industry & 174 & 48 & 228 & 54 & 384 & 27 \\
\hline $\begin{array}{l}\text { General and special } \\
\text { equipment manufacturing }\end{array}$ & 167 & 34 & 545 & 51 & 729 & 80 \\
\hline $\begin{array}{l}\text { Transportation equipment } \\
\text { manufacturing }\end{array}$ & 161 & 44 & 350 & 67 & 282 & 19 \\
\hline $\begin{array}{l}\text { Electrical machinery and equipment } \\
\text { manufacturing }\end{array}$ & 249 & 21 & 493 & 32 & 721 & 42 \\
\hline $\begin{array}{l}\text { Communication equipment, } \\
\text { computers and other electronic } \\
\text { equipment manufacturing }\end{array}$ & 1313 & 33 & 1557 & 56 & 2106 & 37 \\
\hline $\begin{array}{l}\text { Instrumentation and cultural office } \\
\text { machinery manufacturing }\end{array}$ & 153 & 5 & 289 & 5 & 149 & 4 \\
\hline Other manufacturing & 123 & 18 & 78 & 18 & 391 & 41 \\
\hline
\end{tabular}

Note: Calculated based on China's regional non-competitive input-output table data. 
to increase, although the magnitude is not large, but it still shows the rising trend of Jiangsu's manufacturing industry in the global value chain. Of course, the local value-added rate of Jiangsu manufacturing industry is significantly lower than that of the United States and Japan at the top of the value chain, and their indicators are above $80 \%$. Jiangsu's indicators are also lower than that South Korea, which is similar to Taiwan's province. A large number of Taiwanese investment may be the reason for Jiangsu's relatively high local value-added rate. These circumstances indicate that Jiangsu's manufacturing value chain has a long way to go.

Through the decomposition, it can be found that Jiangsu's manufacturing industry and the global value chain division of labor are more closely coordinated, far better than the degree of division of labor with other provinces, autonomous regions and municipalities in China. That is the "outer circulation" of manufacturing is stronger than the "internal circulation". This is an important feature of Jiangsu's manufacturing value chain and an important obstacle to Jiangsu's independent and controllable advanced manufacturing system. It can be seen from Table 2 that in the three years measured, the value added of Jiangsu's manufacturing exports in 2007 and 2010 comes from the proportion of foreign (outside) components, which is significantly higher than that of other provinces, autonomous regions and municipalities in China. This proportion is roughly equal in the year. It can be seen from Table 3 that the typical value chain division of the computer communication equipment and parts manufacturing industry has the lowest proportion of value added in other provinces. Labor-intensive industries such as textiles, clothing, shoes and hats, the proportion of value added in other provinces is also very low. The industries with higher added value in other provinces are mainly metal smelting and rolling, chemical industry, food manufacturing, tobacco industry and petroleum processing industry. The division of labor between Jiangsu's manufacturing industry and overseas has risen to intra-product and intra-industry division of labor. The division of labor with other provinces, autonomous regions and municipalities in China mainly stays at the level of inter-industry division of labor, mainly utilizing the energy resources and bulk primary products of the inlands. While affirming the development of Jiangsu's export-oriented economy, from embedding the global value chain, extending the national value chain to upgrading the independent value chain, it is necessary to recognize that the Jiangsu manufacturing industry chain is largely dominated by foreign multinational companies. On the one hand, multinational corporations will limit the active upgrading of the chain of Jiangsu enterprises and industries. On the other hand, Jiangsu's manufacturing industries and enterprises have been split into the global value chain, lacking autonomy and controllability, and cannot fully utilize the factor endowment advantages and changes of the province and other provinces to layout and upgrade the industry chain. Such a division of value chain structure is also inconsistent with the requirements of regional coordinated development strategies and has the risk of being restricted by international economic and political relations. 


\subsection{Domestic Regional Association of Jiangsu Manufacturing Industry Chain}

Based on China's regional non-competitive input-output table, the value added of Jiangsu's manufacturing exports from other provinces (autonomous regions and municipalities) is further decomposed, Table 4 shows the provincial-level decomposition data of Jiangsu's manufacturing export value added, reflecting the current situation and trend of the spatial structure of the domestic vertical integration of the manufacturing industry chain in Jiangsu.

Table 4. Provincial (regional, municipal) level decomposition of domestic value added of Jiangsu's manufacturing exports (Unit: 100 million).

\begin{tabular}{|c|c|c|c|c|c|c|c|}
\hline \multicolumn{2}{|c|}{ Region/Province } & 2007 & & 2010 & & 2012 & \\
\hline East China $^{*}$ (Yangtze & Zhejiang & \multirow{2}{*}{132} & 95 & \multirow{2}{*}{142} & 111 & \multirow{2}{*}{351} & 236 \\
\hline River Delta) & Shanghai & & 37 & & 31 & & 115 \\
\hline \multirow{5}{*}{$\begin{array}{l}\text { Central China } \\
\text { (includes the } \\
\text { middle reaches } \\
\text { of the Yangtze } \\
\text { River) }\end{array}$} & Anhui & \multirow{5}{*}{188} & 44 & \multirow{5}{*}{263} & 63 & \multirow{5}{*}{664} & 219 \\
\hline & Henan & & 95 & & 121 & & 234 \\
\hline & Hubei & & 13 & & 19 & & 35 \\
\hline & Jiangxi & & 17 & & 33 & & 82 \\
\hline & Hunan & & 19 & & 27 & & 94 \\
\hline \multirow{6}{*}{ North China } & Hebei & \multirow{6}{*}{312} & 123 & \multirow{6}{*}{391} & 146 & \multirow{6}{*}{505} & 168 \\
\hline & Shandong & & 91 & & 113 & & 101 \\
\hline & Shanxi & & 17 & & 33 & & 82 \\
\hline & Beijing & & 16 & & 12 & & 31 \\
\hline & Tianjin & & 29 & & 37 & & 31 \\
\hline & Inner Mongolia & & 36 & & 50 & & 92 \\
\hline \multirow{3}{*}{ South China } & Guangdong & \multirow{3}{*}{113} & 87 & \multirow{3}{*}{167} & 130 & \multirow{3}{*}{189} & 130 \\
\hline & Fujian & & 24 & & 33 & & 56 \\
\hline & Hainan & & 2 & & 4 & & 3 \\
\hline \multirow{3}{*}{ Northeast China } & Liaoning & \multirow{3}{*}{69} & 43 & \multirow{3}{*}{72} & 47 & \multirow{3}{*}{149} & 99 \\
\hline & Jilin & & 16 & & 16 & & 24 \\
\hline & Heilongjiang & & 10 & & 9 & & 26 \\
\hline \multirow{5}{*}{ Northwest China } & Shaanxi & \multirow{5}{*}{67} & 30 & & 49 & \multirow{5}{*}{85} & 48 \\
\hline & Gansu & & 17 & & 26 & & 16 \\
\hline & Qinghai & & 3 & 97 & 6 & & 2 \\
\hline & Ningxia & & 7 & & 6 & & 7 \\
\hline & Xinjiang & & 10 & & 10 & & 12 \\
\hline \multirow{6}{*}{ Southwest China } & Chongqing & \multirow{6}{*}{51} & 6 & \multirow{6}{*}{76} & 15 & \multirow{6}{*}{128} & 26 \\
\hline & Sichuan & & 15 & & 27 & & 30 \\
\hline & Guizhou & & 7 & & 10 & & 11 \\
\hline & Yunnan & & 9 & & 10 & & 33 \\
\hline & Guangxi & & 14 & & 14 & & 28 \\
\hline & Xizang & & $<1$ & & $<1$ & & $<1$ \\
\hline
\end{tabular}

Note: Calculated based on China's regional non-competitive input-output table data. * The country's latest Yangtze River Delta integration strategic plan includes Anhui Province. 
First of all, the tightness of the distribution of the Jiangsu manufacturing industry chain among various regions in China is highly positively correlated with the spatial proximity. The value added of Zhejiang, Shanghai, Henan, Shandong, and Anhui exceed 10 billion yuan in the most recent year, which is in line with the gravitational model of trade theory and the law explained by the relevant theories of spatial economics. Zhejiang, which contributed the most to Jiangsu's exports. The fastest rising contribution to Jiangsu's exports is Anhui. Second, whether it is global value chain or national value chain, a value chain refers to a production trade system based on the division of labor within products. Hebei, Henan, Shandong, Inner Mongolia and other provinces and regions have higher proportions of value added exports in Jiangsu, which have greater relationships with Jiangsu's demand for energy resources and primary products. This is an inter-industry or intra-industry division of labor, and of course the basis for building a manufacturing value chain. Third, from the exact meaning of the value chain, the domestic spatial distribution of Jiangsu's manufacturing is mainly in the Yangtze River Delta region, Guangdong in southern China and neighboring Anhui, Henan and Shandong. Fourth, from the perspective of timing dynamics, the interaction between Jiangsu and Zhejiang, Shanghai, Anhui, Henan, Shandong and other provinces in the manufacturing value chain has increased significantly. The integration of Jiangsu and Guangdong is stable, which may be related to the high similarity and competitive relationship between the two provinces.

Continue to fully open up, absorb the global high-end manufacturing factors, construct an advanced manufacturing industry chain oriented to the world, implement regional coordinated development strategies and strengthen coordinated economic development with provinces, autonomous regions and municipalities across the country. These are the premises for Jiangsu to build an independent and controllable advanced manufacturing system. Under these premises, Jiangsu's advanced manufacturing value chain construction has a "core space" and "two spatial expansion directions." The core space is the Yangtze River Delta region. Shanghai has the advantages of financial centers, science and technology centers, high-end talents and some high-end manufacturing industries. Zhejiang also has advantages in specialized talents, technology transformation and key manufacturing sectors, with strong market and business model innovation in the forefront of the country. Jiangsu is a large province of science and education with good economic foundation and developed manufacturing industry. Anhui has advantages in science and technology, talents, factor resources and the transfer of some industries. The four provinces have different endowments and strong complementarities. For example, Zhejiang has advantages in the new generation of Internet applications. Jiangsu has advantages in the new generation of Internet hardware manufacturing. The Yangtze River Delta region has the realistic foundation for building an innovation chain and an industrial chain. Two spatial expansion directions: The first is the Yangtze River Economic Belt. Anhui has included. Jiangxi and Hunan have increased their share of Jiangsu's value added exports. Hubei's scientific and technological ad- 
vantages and industrial structure are significantly different from Jiangsu, and there is great room for complementary development. The second is the Huaihai Economic Zone. Expanding along the New Silk Road Economic Belt, through the combination of new generation of information Internet technology and equipment manufacturing, to build an industrial Internet system covering Shandong, Henan and beyond, with realistic industrial cooperation basis and in line with the national development strategy intentions. In addition, maintaining and strengthening the competitive cooperation relationship with the Guangdong manufacturing value chain is of great significance. The competition, interaction, differentiation and restructuring between the chains are the highest forms of value chain upgrading.

\subsection{Value Added Comparative Advantages of Jiangsu Manufacturing Industry Segments}

Due to space limitation, the paper does not give a comparative analysis of the comparative advantage of Jiangsu's added value (VRCA) and the comparative advantage of gross value (RCA). In addition, both VRCA and RCA are terrestrial comparative advantages and are the result of a comprehensive calculation of the local and foreign economic components of Jiangsu. The comparative advantage of Jiangsu's local manufacturing industry is exactly how the ownership comparative advantage is, and it needs to be comprehensively evaluated in combination with the proportion of FDI in various industries. Table 5 shows the VRCA of 16 industries and the proportion of FDI in various industries.

The equations are an exception to the prescribed specifications of this template. You will need to determine whether or not your equation should be typed using either the Times New Roman or the Symbol font (please no other font). Equations should be edited by Mathtype, not in text or graphic versions. You are suggested to use Mathtype 6.0 (or above version).

According to the value added comparative advantage and the proportion of foreign investment, combined with the proportion of relevant industries in Jiangsu's industrial value added and the requirements of "Made in China 2025" and high-quality development, while considering the applicability of the division of labor in different industry value chains, the true comparative advantages of Jiangsu's local industries is specifically analyzed. 1) The manufacturing of communication equipment, computers and other electronic equipment is one of the pillar industries of Jiangsu. The industry has a significant comparative advantage in value added, but it has a fluctuating downward trend. At the same time, the industry has the highest proportion of average FDI. Its comparative advantage comes from foreign capital, and the real competitiveness of the local industry is not as good as the appearance. This is the biggest "pain point" of the industry. As a typical value chain division of labor industry, this industry is a key industry in Jiangsu that needs to strengthen independent innovation and build its own value chain. 2) The value added comparative advantage of instrumentation, culture 
Table 5. Comparative advantages of added value of Jiangsu manufacturing industry segment and foreign capital ratio of industry.

\begin{tabular}{|c|c|c|c|c|c|c|}
\hline \multirow{2}{*}{ Manufacturing Industry } & \multicolumn{3}{|c|}{ VRCA } & \multicolumn{3}{|c|}{ FDI Industry Share } \\
\hline & 2007 & 2010 & 2012 & 2007 & 2010 & 2012 \\
\hline Food and tobacco processing industry & 0.65 & 0.82 & 0.51 & $45 \%$ & $24 \%$ & $17 \%$ \\
\hline Textile industry & 1.70 & 1.47 & 1.41 & $41 \%$ & $28 \%$ & $20 \%$ \\
\hline $\begin{array}{l}\text { Clothing, shoes, hats, leather } \\
\text { and other products industry }\end{array}$ & 1.00 & 0.99 & 1.03 & $81 \%$ & $56 \%$ & $41 \%$ \\
\hline $\begin{array}{l}\text { Wood processing and furniture } \\
\text { manufacturing }\end{array}$ & 0.75 & 0.91 & 0.80 & $41 \%$ & $26 \%$ & $18 \%$ \\
\hline $\begin{array}{l}\text { Paper printing, cultural and educational } \\
\text { sporting goods manufacturing }\end{array}$ & 0.90 & 0.96 & 0.62 & $70 \%$ & $58 \%$ & $43 \%$ \\
\hline $\begin{array}{l}\text { Petroleum processing, coking and nuclear } \\
\text { fuel processing industry }\end{array}$ & 0.49 & 0.73 & 0.47 & $79 \%$ & $45 \%$ & $28 \%$ \\
\hline chemical industry & 1.22 & 1.22 & 1.73 & $43 \%$ & $29 \%$ & $20 \%$ \\
\hline Non-metallic mineral products industry & 0.53 & 0.73 & 0.87 & $58 \%$ & $33 \%$ & $19 \%$ \\
\hline $\begin{array}{l}\text { Metal smelting and rolling } \\
\text { processing industry }\end{array}$ & 0.91 & 0.90 & 1.35 & $27 \%$ & $22 \%$ & $14 \%$ \\
\hline Metal products industry & 0.91 & 1.10 & 1.44 & $56 \%$ & $27 \%$ & $17 \%$ \\
\hline $\begin{array}{l}\text { General and special equipment } \\
\text { manufacturing }\end{array}$ & 0.65 & 1.37 & 1.42 & $56 \%$ & $33 \%$ & $24 \%$ \\
\hline Transportation equipment manufacturing & 0.86 & 1.11 & 1.00 & $49 \%$ & $27 \%$ & $19 \%$ \\
\hline $\begin{array}{l}\text { Electrical machinery and } \\
\text { equipment manufacturing }\end{array}$ & 1.01 & 1.21 & 1.60 & $88 \%$ & $53 \%$ & $31 \%$ \\
\hline $\begin{array}{l}\text { Communication equipment, computers and } \\
\text { other electronic equipment manufacturing }\end{array}$ & 2.00 & 1.76 & 1.83 & $87 \%$ & $59 \%$ & $42 \%$ \\
\hline $\begin{array}{l}\text { Instrumentation and cultural office } \\
\text { machinery manufacturing }\end{array}$ & 1.43 & 1.93 & 2.15 & $70 \%$ & $26 \%$ & $14 \%$ \\
\hline Other manufacturing & 1.15 & 0.61 & 2.96 & $16 \%$ & $12 \%$ & $11 \%$ \\
\hline
\end{tabular}

Note: Calculated according to formula (5) by Matlab. ${ }^{\star}$ The construction and calculation of this index have been explained in the second part of the article.

and office machinery manufacturing is the highest and on the rise, with low average foreign investment ratio. They are the most competitive industries in Jiangsu and knowledge-intensive and high value-added intermediate demand industries, which meet the requirements of high quality development. The "pain point" of the industry is currently not very high in the gross industrial output of Jiangsu. 3) General and special equipment manufacturing is a rapidly rising industry in Jiangsu in recent years. The comparative advantage of added value is significant and rising. The proportion of foreign investment is not high, indicating that the comparative advantage of the industry is more from the competitiveness of local industries. This industry is one of the key industries of "Made in China 2025". It should be Jiangsu to build a key planning industry with inde- 
pendent controllable value chain. 4) The chemical industry is currently one of the pillar industries in Jiangsu. It has comparatively significant value added comparative advantage and the lowest proportion of foreign investment. The industry can strengthen independent innovation and become a basic industry for many advanced manufacturing industries such as new materials and high-tech pharmaceuticals. 5) Electrical machinery and equipment manufacturing is currently a relatively large industry in Jiangsu's manufacturing output. In addition to general electrical machinery and equipment, including solar cells, lithium batteries (HS code 3841-3849), robotics industry (HS coding) 8428-8543), etc., the industry has comparative advantage and is on the rise. The average foreign investment is relatively high. The real competitiveness of the local industry needs to be further improved. 6) Jiangsu's textile industry has significant VRCA, and the proportion of foreign investment is low. It is an industry with real comparative advantages. There is no comparative advantage in the clothing, shoes, hats, leather and down products industry. Therefore, it is not rigorous to mix textiles and garments together. Jiangsu should continue to retain the textile industry and climb to high-end textiles.

The data of the above analysis is as of 2012. In recent years, new energy industries such as photovoltaics and wind power, new materials such as metal nano-, inorganic and organic nano-materials and new generation information technology products formed by Jiangsu in the process of industrial transformation and upgrading and high-quality development have been included in the classified industry, but new developments after 2012 cannot be reflected. Some new industries across the manufacturing and service industries, such as artificial intelligence and the Internet of Things can only reflect the hardware. If a high-tech industry does not export, the technical framework of this article cannot assess its true competitiveness. But in general, the existing industrial base and the integrity of the industry that is the length of the industrial chain, the core technology, the control of the core links, etc. determine the true competitiveness of the industry, and also the basis for the integration and upgrading of the chain. The above research results have high reference value.

\section{Conclusions and Policy Suggestions}

\subsection{Conclusions}

The Sino-US trade conflict, decline of economic globalization and restructuring of global value chains have strengthened the necessity and urgency of building an open docking, autonomous and controllable domestic value chain. Jiangsu is a big manufacturing and open province. The goal, path and measures of Jiangsu's "building an independent and controllable advanced manufacturing system" have typical reference value. According to the decomposition framework of KWW export value-added, this paper decomposes Jiangsu manufacturing value added exports by using the data of World Input-Output Table (WIOT) and China's inter-regional non-competitive input-output table. It is found that the 
import component of Jiangsu's value added exports is higher than that of other provinces, regions and cities. The division of labor between Jiangsu's manufacturing industry and global value chain has risen to the level of intra-product division of labor. However, the division of labor with other provinces and municipalities in China is relatively low, which indicates that Jiangsu's economy has the characteristics of "external circulation", stronger than "internal circulation". The relatively low local value-added rate is a common feature of developing open economies and coastal areas of China. However, the lack of core technology, the lack of autonomy and integration of the value chain may not only affect the profit of the value chain, but also restrict the upgrading of the value chain. In the face of the current and future economic globalization and the turbulent international economic and political environment, the necessity and urgency of building an autonomous and controllable manufacturing value chain are unprecedentedly enhanced. This paper calculates the comparative advantage of value added of 16 manufacturing industry subdivisions in Jiangsu, and combines the proportion of foreign investment in each industry to analyze the real competitiveness of the main manufacturing industries in Jiangsu. Communications equipment, computers and artificial intelligence based on them, instrument and cultural office machinery manufacturing, general and special equipment, electrical machinery and robots, chemical industry and new materials are industries with real local competitive advantages in Jiangsu, of course, all industries also have disadvantages. Textile and clothing cannot be "confused", Jiangsu textile industry has a real local competitive advantage, while clothing, shoes, hats, leather and down products have lost the overall comparative advantage. These conclusions can be used as a reference for Jiangsu to build an independent and controllable manufacturing value chain system. Through further decomposition of the sources of provinces, districts and cities outside Jiangsu's value added exports, the paper analyses the current situation and trend of the domestic regional correlation of Jiangsu's manufacturing industry. According to the characteristics of industrial structure and factor advantages of relevant provinces, it is considered that the core space of national value chain construction of Jiangsu manufacturing industry is the Yangtze River Delta, and the extension of the Yangtze River Economic Zone and Huaihai Economic Zone along the New Silk Road Economic Zone is the two main directions of spatial expansion.

\subsection{Policy Suggestions}

Thus, the policy suggestions can be summarized as follows:

- Continue to promote comprehensive opening-up at a higher level and with higher quality. Building an independent and controllable manufacturing system is by no means a "closed door" manufacturing system. Only in an open competitive environment can we forge "advanced nature". The reason why Jiangsu has relatively high local value-added rate in coastal provinces and cities lies in the early implementation of selective investment attraction and a 
series of high-quality open measures in Jiangsu, thus laying a foundation for the establishment of independent value chain for some industries. Building an independent value chain does not deny that enterprises in many industries continue to embedded, extend and climb the global value chain. Only in this way can we truly achieve open integration and self-control.

- Push Jiangsu's open economy to a new stage. The key to self-control is that core technology must be mastered in their own hands and self-centered innovation chain must be constructed. While giving full play to the role of high-end talents in our province and our country, we must shift from the focus of attracting investment to the focus of "attracting wisdom", and absorb the global high-end elements to build an independent innovation system. The driving force and direction of a country's technological innovation system cannot be the demand of foreign markets. The market side of the self-regulated industry chain should focus on upgrading domestic demand, and at the same time, build up production chains and demand chains through external investment and the global market, especially the countries along the belt and road. This is the connotation of the new stage of Jiangsu's open economy and the requirement of high-quality development.

- In order to give full play to the comparative advantages of Jiangsu's real competitive industries, we should not only be forward-looking, but also adhere to the principle of doing something, not doing something, so as to avoid the rushing up of seemingly big industries at this stage. It is impossible for a country to establish an industrial chain in all industries and cover all links of the chain, especially in a province.

- We should pay attention to the "local market effect" and "big market effect" and accelerate the deepening of the integration strategy of the Yangtze River Delta, especially the construction of the free flow of talents, the science and technology financial system and the regional innovation chain. We will pragmatically promote the construction of the Yangtze River Economic Zone and the expansion of the Huaihai Economic Zone to the new Silk Road Economic Zone, improve the quality of infrastructure interconnection, give full play to their respective factor endowments and location advantages, and rationally arrange innovation chains, production chains and their integration through the new generation of mobile Internet.

- The formation of value chain system is the result of market self-organization, and better playing the role of the government should be embodied in providing higher quality system supply, strengthening the protection of intellectual property rights, creating a fair competitive market environment, breaking administrative barriers and so on. It is particularly urgent for Jiangsu to cultivate leading enterprises in related industries. Enterprises should be the main body, follow the market mechanism and consider international rules.

\section{Conflicts of Interest}

The authors declare no conflicts of interest regarding the publication of this paper. 


\section{References}

[1] Wang, L. (2000) China Foreign Investment Report 2000. Economic Science Press, Beijing.

[2] Jiang, X. (2002) China's Foreign Capital Economy. China Renmin University Press, Beijing.

[3] Zhang, E. (2005) Globalization, Division of Factors and China's Strategy. Xinhua Digest, Beijing.

[4] Gereffi, G. (1999) International Trade and Industrial Upgrading in the Apparel Commodity Chains. Journal of International Economics, 48, 37-70. https://doi.org/10.1016/S0022-1996(98)00075-0

[5] Li, X. (2004) Thinking on “Trading Domestic Market for Technology" under the WTO Framework. China Industrial Economy, No. 4, 21-26.

[6] Xu, J. (2006) On the Impoverished Growth of China's Foreign Capital Economy. Journal of Nanjing Normal University (Social Science Edition), No. 6, 69-73.

[7] Ping, X. (2007) Has the Market Exchanged Technology? International Economic Review, No. 5, 33-36.

[8] Liu, Z. and Zhang, J. (2007) Forming, Breakthrough and Strategies of Captive Network in Developing Countries at Global Outsourcing System: Based on a Comparative Survey of GVC and NVC. China Industrial Economy, No. 5, 39-47.

[9] Li, G. and Pan, W. (2016) How Do Domestic Value Chains Embed into Global Value Chains? Perspective from Value Added. China Industrial Economy, No. 7, 10-22.

[10] Li, F. (2017) Imports, Local Economic Linkages and Reshape of National Value Chain. China Industrial Economy, No. 9, 25-43.

[11] Hummels, D., Ishii, J. and Yi, K. (2001) The Nature and Growth of Vertical Specialization in World Trade. Journal of International Economics, 54, 75-96. https://doi.org/10.1016/S0022-1996(00)00093-3

[12] Koopman, R., Wang, Z. and Wei, S.J. (2012) Estimating Domestic Content in Exports When Processing Trade Is Pervasive. Journal of Development Economics, 99, 178-189. https://doi.org/10.1016/j.jdeveco.2011.12.004

[13] Johnson, R.C. and Noguera, G. (2012) Accounting for Intermediates: Production Sharing and Trade in Value Added. Journal of International Economics, 86, 224-236. https://doi.org/10.1016/j.jinteco.2011.10.003

[14] Wang, Z., Wei, S.J. and Zhu, K.F. (2013) Quantifying International Production Sharing at the Bilateral and Sector Levels. NBER Working Paper No. 19677.

[15] Koopman, R., Wang, Z. and Wei, S.J. (2014) Tracing Value Added and Double Counting in Gross Exports. American Economic Review, 104, 459-494. https://doi.org/10.1257/aer.104.2.459

[16] Liu, Z. (2007) Non-Competitive Input-Occupied Output Model and Its Application: Perspective of Sino-US Trade Surplus. Chinese Social Sciences, No. 5, 91-103.

[17] Deng, J. (2013) Evaluation of China's Manufacturing Export Competitiveness from the Perspective of Value Added Trade. Journal of Zhongnan University of Economics and Law, No. 5, 40-72.

[18] Wang, K. and Liao, H. (2016) Domestic Input, Intermediate Import and FDI Vertical Spillover-An Empirical Study Based on Non-Competitive Input-Output Table. Quantitative Economics and Economics Research, No. 1, 89-103.

[19] Wang, L. (2018) Accounting of Bilateral Trade Gains in Global Value Chains: An Empirical Study on China Export to the US. International Trade Issues, No. 2, 
$81-91$.

[20] Zhang, S. (2010) Is Regional Integration a "Stepping Stone" or a Stumbling Block to the Domestic Value Chain? Finance and Trade Economy, No. 11, 118-124.

[21] Wu, Q., Liu, Z. and Jiang, J. (2011) New Strategic Choice of Improving the Level of Opening up in Yangtze River Delta under Expanding Domestic Demand. Shanghai Economic Research, No. 10, 21-28.

[22] Su, Q. (2016) Tracing Value Added in China's Exports at the Provincial Level. Economic Research, No. 1, 84-113.

[23] Li, F., Liu, S. and Tang, Z. (2016) Estimation of Value-Added in Provincial Exports and Its Impact on Industrial Structure. Tropical Geography, 36, 1026-1033.

[24] Li, G. and Pan, W. (2016) How Domestic Value Chains Are Embedded in Global Value Chains: A Perspective of Value Added. China Industrial Economy, 7.

[25] Ni, H. and Xia, J. (2016) The Role and Changes of China's Region in the Global Value Chain. Finance and Trade Economy, 10.

[26] Pan, W. and Li, G. (2018) National Value Chain and Global Value Chain in Chinese Regions: Regional Interaction and Value-Added Gains. Economic Research, No. 3, 171-186. 